Supporting Information to Accompany

\title{
Covalently Linked, Two-Dimensional Quantum Dot Assemblies
}

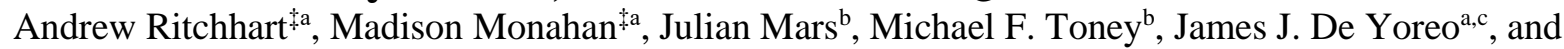
Brandi M. Cossairt*a

aUniversity of Washington, Department of Chemistry, Box 351700, Seattle, WA 98195-1700.

${ }^{b}$ Stanford Synchrotron Radiation Lightsource, SLAC National Accelerator Laboratory, Menlo Park, CA 94025.

'Physical Sciences Division, Pacific Northwest National Laboratory, Richland, WA 99354.

* cossairt@uw.edu

Number of Pages: $\quad 19$

Number of Figures: $\quad 14$

Number of Schemes: 0

Number of Tables: 5

Experimental Methods.

Page S3 - S7

SAXS Fitting Details.

Page S11 - S12

References.

Page S19

\section{List of Figures.}

$\mathrm{S} 1$. TEM images of amorphous QD aggregates after $1 \mathrm{~h}$ equilibration at $22{ }^{\circ} \mathrm{C}$ with varied linker equivalents.

Page S8

S2. DLS data for CdS QD aggregates prior to thermal equilibration as a function of linker concentration.

Page S8

S3. Single crystal X-ray diffraction structure of (bpy)2Ru(2,2'-bpy-5,5'-diacrylic acid). Page S9

S4. TEM images of CdS quantum dots that have been subjected to standard assembly conditions using a monofunctional carboxylic acid, cinnamic acid, which does not lead to productive assembly.

Page S10

S5. DLS data for CdS assemblies suspended in toluene as a function of QD concentration during assembly.

Page S12

S6. Solution phase UV-Vis spectrum of CdS QDs (blue) and diffuse reflectance spectrum of a thin film of CdS QDs linked by 2,2'-bipyridine-5,5'-diacrylic acid.

Page S12

S7. TEM images of particles following treatment of CdS QDs with different linkers. Page S13

S8. TEM images of assemblies prepared from InP/ZnSe (A), InP clusters (B), and CdSe (C-G) QDs using standard conditions.

Page S14

S9. TEM images of assemblies prepared from InP/ZnSe QDs showing segregation of core and core/shell

QDs in separate structures.

Page S14

S10. TEM images of assemblies prepared from polydisperse CdS QDs showing segregation of two QD sizes into separate structures.

Page S15

S11. EDS mapping of CdS assemblies exposed to $\mathrm{Ni}^{2+}$ showing co-localization of Cd (blue), $\mathrm{S}$ (red), and $\mathrm{Ni}$ (yellow).

Page S15

$\mathrm{S} 12$. ICP-MS data quantifying $\mathrm{Ni}^{2+}$ uptake in $\mathrm{CdS}$ assemblies. In the case of $\mathrm{Ni}$ addition pre-assembly, $\mathrm{NiCl}_{2}\left(\mathrm{PPh}_{3}\right)_{2}$ was added to a solution of the bpy-diester before addition to the QDs. Page S16 S13. Additional TEM images for CdS (A-C) and CdSe (D-F) QDs assembled using 10 eq. 2,2'bipyridine-5,5'-diacrylic acid.

Page $\mathrm{S} 17$ S14. Histograms of particle spacing for aggregates and QDs of varying core compositions and histograms of CdS cores with different linkers.

Page S18 


\section{List of Tables.}

S1. Particle size and spacing analysis for CdS QDs.

Page S9

S2. Crystal data table for (bpy $)_{2} \mathrm{Ru}(2,2$ '-bpy-5,5'-diacrylic acid $) \mathrm{Cl}_{2}$.

Page S9-S10

S3. SAXS Fitting.

Page S10

S4. Particle size and spacing analysis for different linkers.

Page S13

S5. Particle size and spacing analysis for $\mathrm{CdSe}$ and $\mathrm{InP} / \mathrm{ZnSe} \mathrm{QDs}$ after aggregation.

Page S14 


\section{Experimental Methods.}

\section{Materials.}

Indium acetate (99.99\%), oleic acid (99\%), zinc stearate (90\%), cadmium oxide $(99.99 \%)$, selenium powder 100 mesh (99.99\%), sulfur powder (99\%), 2,5-dibromopyridine (98\%), 4,4'-dibromobiphenyl (98\%), tert-butyl acrylate (98\%), palladium acetate (99.9\%), triethanolamine (98\%), Xphos (97\%), tetramethyl thiourea (98\%), dodecanedioic acid (99\%), terepthalic acid (99\%), 2,2'-bipyridine-4,4'dicarboxylic acid (90\%), and ICP-MS grade nitric acid were purchased from Sigma-Aldrich and used without further purification. NMR solvents were purchased from Cambridge Isotope Laboratories, dried over calcium hydride, vac-transferred, and stored over dried $4 \AA$ molecular sieves under $\mathrm{N}_{2}$ in a glovebox. Solvents were either dried over calcium hydride and distilled or obtained dry from a solvent system utilizing alumina and Q5 columns. All solvents were stored in a glovebox over $4 \AA$ molecular sieves prior to use. Acetonitrile (99.8\%, anhydrous) was purchased from Sigma-Aldrich and used without further purification. Tris(trimethylsilyl)phosphine $\left(\mathrm{P}\left(\mathrm{SiMe}_{3}\right)_{3}\right)$ was synthesized according to literature procedure. ${ }^{1}$

\section{General Practices.}

Unless stated otherwise, all chemical reactions were performed under $\mathrm{N}_{2}$ using standard Schlenk line airfree techniques. Chemicals were stored dried in a $\mathrm{N}_{2}$ glovebox unless stated otherwise. Purified quantum dots were stored in stock solutions in toluene and concentrations were determined by UV-Vis spectroscopy. ${ }^{2,3}$ All other chemicals were stored dried and stock solutions for their use were made and used within $8 \mathrm{~h}$.

\section{Synthesis of CdS QDs.}

CdS QDs were synthesized using an adapted literature method using tetramethyl thiourea and cadmium oleate $\left(\mathrm{CdOl}_{2}\right)$ precursors. ${ }^{4} \mathrm{In}$ a glovebox, a $500 \mathrm{~mL}$ three neck round-bottomed flask was charged with

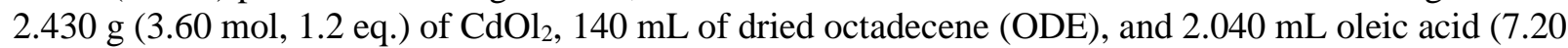
mmol, 2.4 eq.), and the vessel was transferred to a Schlenk line. Due to the lack of solubility in ODE, for the injection medium a mixture of $74 \%$ diphenyl ether and $26 \%$ biphenyl was prepared. In the glovebox, $396 \mathrm{mg}$ ( $3.00 \mathrm{mmol}, 1.0$ eq.) of tetramethyl thiourea was measured and dissolved in $5.0 \mathrm{~mL}$ of this mixture. The reaction vessel was raised to $230{ }^{\circ} \mathrm{C}$ and the thiourea was swiftly injected and allowed to react for $2 \mathrm{~h}$. QD purification was performed in air. The particles were precipitated with acetone and isolated via centrifugation at 10,000 rpm. The particles were resuspended in $60 \mathrm{~mL}$ hexanes (divided) and precipitated again with acetone. The particles were then resuspended in $40 \mathrm{~mL}$ toluene and precipitated with $90 \mathrm{~mL}$ acetonitrile; this was repeated a total of three times. Drying in vacuo yielded a free-flowing yellow powder. Dried yield: 576 mg. Emission $476 \mathrm{~nm} \pm 14 \mathrm{~nm}$ FWHM, PLQY 81\%.

\section{Synthesis of CdSe QDs.}

CdSe QDs were synthesized using an adapted method using selenourea and cadmium oleate precursors. ${ }^{4}$ The procedure was performed as described using diphenyl-imidazole selenourea on a $2.5 \mathrm{mmol} \mathrm{CdOl}_{2}$ scale. The product was isolated as an orange wax. Emission $527 \mathrm{~nm} \pm 16 \mathrm{~nm}$ FWHM, PLQY 36\%.

Synthesis of InP/ZnSeS QDs.

$\mathrm{InP} / \mathrm{ZnSeS}$ QDs were prepared as described by in the literature. ${ }^{5}$ The procedure was performed as described on a $0.11 \mathrm{mmol}$ In scale. The product was isolated as an orange wax. Emission $605 \mathrm{~nm} \pm 25 \mathrm{~nm}$ FWHM, PLQY 60\%.

\section{Synthesis of Linkers.}

2,2'-bipyridine-5,5'-diacrylate-tBu was synthesized using a palladium catalyzed double Heck cross coupling as previously reported on the $3 \mathrm{mmol}$ scale ${ }^{6}$ The crude product was filtered and recrystallized from acetone. ${ }^{1} \mathrm{H}$ NMR (300 MHz, Methylene Chloride- $\left.d_{2}\right) \delta 8.78(\mathrm{~d}, J=2.2 \mathrm{~Hz}, 2 \mathrm{H}), 8.48(\mathrm{~d}, J=8.3 \mathrm{~Hz}$, 2H), 7.99 (dd, $J=8.4,2.3 \mathrm{~Hz}, 2 \mathrm{H}), 7.62(\mathrm{~d}, J=16.1 \mathrm{~Hz}, 2 \mathrm{H}), 6.51(\mathrm{~d}, J=16.1 \mathrm{~Hz}, 2 \mathrm{H}), 1.54(\mathrm{~d}, J=3.1$ $\mathrm{Hz}, 18 \mathrm{H})$. Mass Spec Theoretical m/z $\left(\mathrm{MH}^{+}\right)$409.2122, Found: m/z $\left(\mathrm{MH}^{+}\right) 409.2118$. 


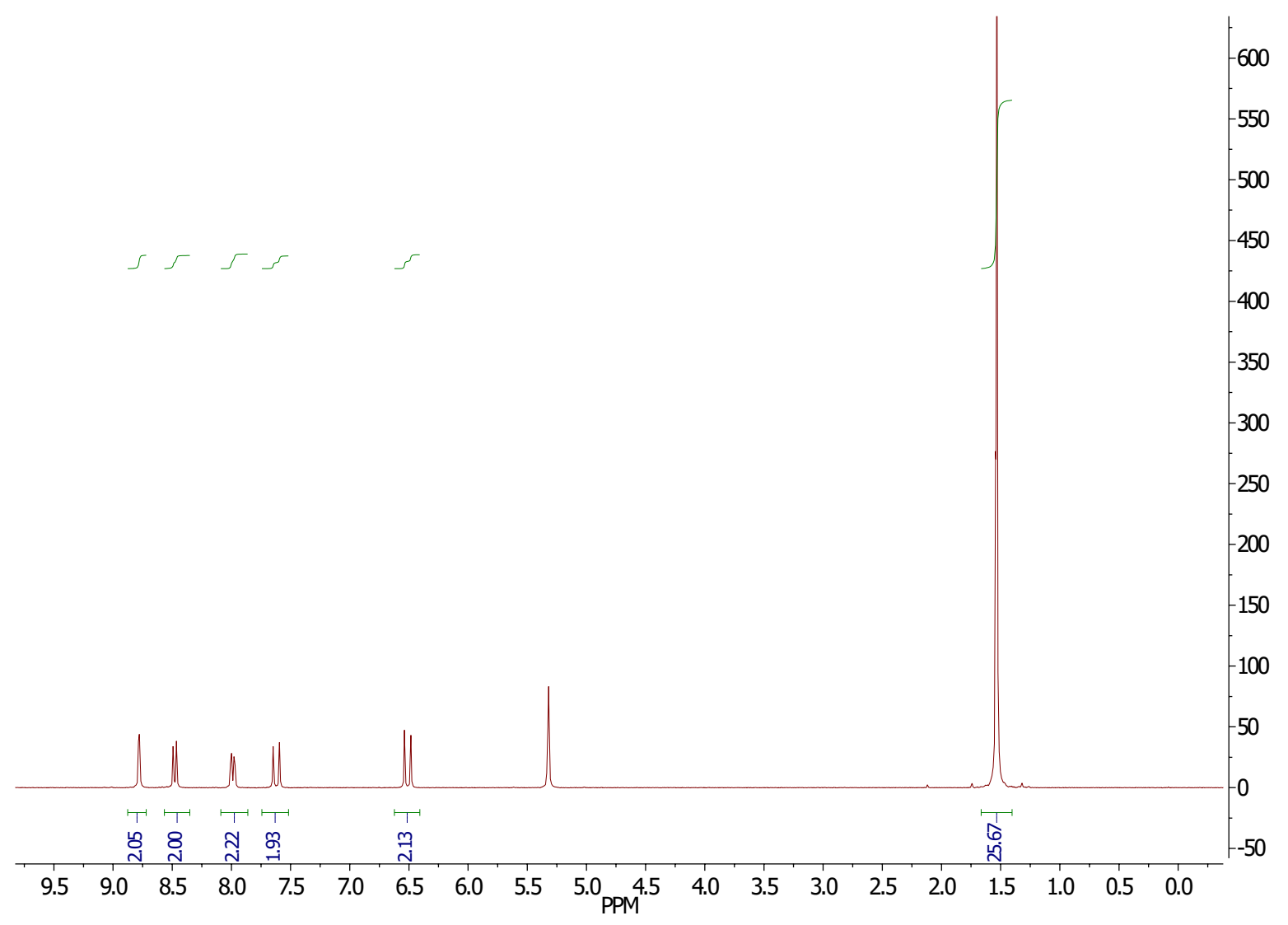

The ester group was cleaved by the addition of TFA and phenol in $\mathrm{CH}_{2} \mathrm{Cl}_{2}$ as described for $\mathrm{Ru}(\text { bpy })_{2}($ bpyCOOH$) \mathrm{Cl}_{2}$ below, however the product is remarkably insoluble and was only observed to dissolve in basic aqueous solution and hot DMF. ${ }^{1} \mathrm{H}$ NMR (300 MHz, Deuterium Oxide) $\delta 8.64(\mathrm{~s}, 2 \mathrm{H})$, $8.14-7.87(\mathrm{~m}, 4 \mathrm{H}), 7.30(\mathrm{~d}, J=16.1 \mathrm{~Hz}, 2 \mathrm{H}), 6.55(\mathrm{~d}, J=16.2 \mathrm{~Hz}, 2 \mathrm{H})$.

2,2'-biphenyl-5,5'-diacrylate-tBu was synthesized using an adapted procedure involving a phosphine-free Heck cross coupling. ${ }^{7}$ A 100 mL Schlenk flask was loaded with 1.872 g 4,4'-dibromo-biphenyl (6.0 mmol, 1.0 eq.), $1.538 \mathrm{~g}$ tertbutyl acrylate $(12.0 \mathrm{mmol}, 2.0$ eq. $), 31 \mathrm{mg}$ palladium acetate $(0.12 \mathrm{mmol}, 0.02$ eq.), and $24 \mathrm{~mL}$ triethanolamine. Triethanolamine was dried over $4 \AA$ molecular sieves and degassed under vacuum prior to use. The vessel was equipped with a condensing column and raised to $100{ }^{\circ} \mathrm{C}$ for $14 \mathrm{~h}$. The cloudy brown reaction mixture was diluted with $50 \mathrm{~mL} \mathrm{CH}_{2} \mathrm{Cl}_{2}$ and filtered. The soluble phase was then extracted three times with $50 \mathrm{~mL}$ portions of $\mathrm{H}_{2} \mathrm{O}$. The organic layer was dried over $\mathrm{MgSO}_{4}$, filtered, and the solvent was removed using a rotovap. The resulting yellow-white powder was dissolved in $4 \mathrm{~mL} \mathrm{CH}_{2} \mathrm{Cl}_{2}$ and layered with $10 \mathrm{~mL}$ hexanes, immediately yielding 2,2'-biphenyl-5,5'-diacrylate-tBu as crystalline white flakes. ${ }^{1} \mathrm{H}$ NMR $\left(300 \mathrm{MHz}\right.$, Methylene Chloride- $\left.d_{2}\right) \delta 7.61(\mathrm{~d}, J=15.8 \mathrm{~Hz}, 10 \mathrm{H})$, $6.42(\mathrm{~d}, J=16.0 \mathrm{~Hz}, 2 \mathrm{H}), 1.53(\mathrm{~s}, 18 \mathrm{H})$. 


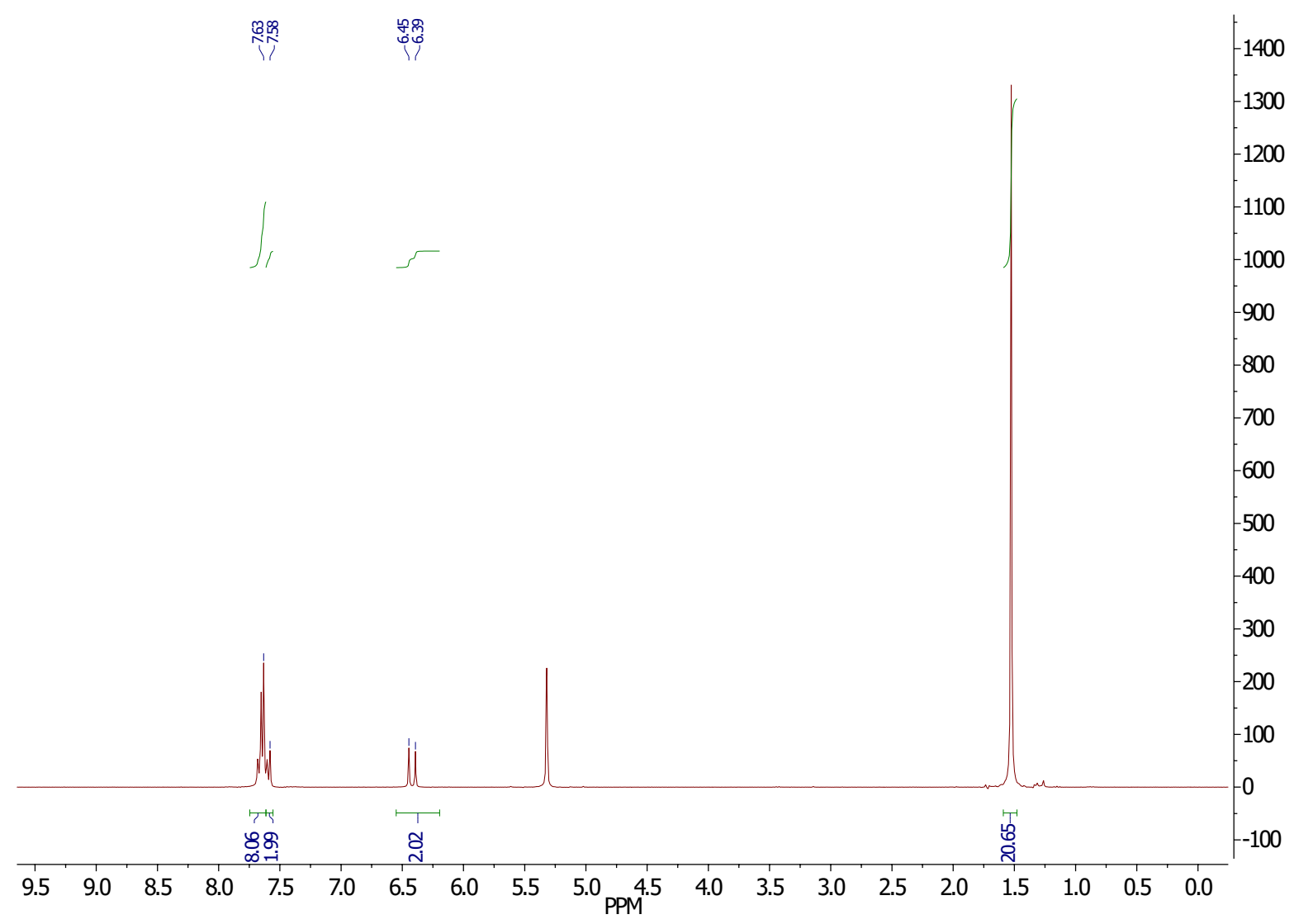

\section{Synthesis of $\mathrm{Ru}(\mathrm{bpy})_{2}\left(2,2^{\prime}\right.$-bpy-5,5'-diacrylic acid $) \mathrm{Cl}_{2}$.}

A round bottom flask was loaded with $108 \mathrm{mg}$ of $\mathrm{Ru}(\mathrm{bpy})_{2} \mathrm{Cl}_{2}(0.223 \mathrm{mmol}, 1$ eq. $)$ and $100 \mathrm{mg} 2,2^{\prime}-$ bipyridine-5,5'-diacrylate-tBu $(0.245 \mathrm{mmol}, 1.1 \mathrm{eq}$.) and charged with $35 \mathrm{~mL} 200$ proof EtOH. The Solution was sparged with $\mathrm{N}_{2}$ for 10 min and then the vessel was equipped with a condensing column and connected to a Schlenk line under $\mathrm{N}_{2}$. The solution was refluxed with stirring for $5 \mathrm{~h}$. The resulting deep red solution was allowed to cool, and the solvent was removed by rotovap leaving a dark red-black solid. The solid was dissolved in $15 \mathrm{~mL} \mathrm{H}_{2} \mathrm{O}$, filtered through a glass frit leaving a black solid, and the eluent was dried via rotovap at $50{ }^{\circ} \mathrm{C}$. The product, $\mathrm{Ru}(\mathrm{bpy})_{2}\left(2,2^{\prime}-\mathrm{bpy}-5,5^{\prime}\right.$-diacrylate- $\left.\mathrm{tBu}\right) \mathrm{Cl}_{2}$, was isolated as a dark red powder, $73 \mathrm{mg}, 40 \%$ yield.

For ester cleavage, the esterified complex was dissolved in $2 \mathrm{~mL} \mathrm{CH}_{2} \mathrm{Cl}_{2}$ (82 umol, 1.0 eq.), and $166 \mathrm{mg}$ phenol (1.7 mmol, 20.0 eq.), and $0.15 \mathrm{~mL}$ trifluoroacetic acid ( $0.9 \mathrm{mmol}, 11$ eq.) were added. The solution was stirred at room temperature for $2 \mathrm{~h}$. Solvent and excess phenol were removed under vacuum at elevated temperature. The remaining powder was dissolved in $1 \mathrm{~mL} \mathrm{CH}_{2} \mathrm{Cl}_{2}$, layered with $5 \mathrm{~mL}$ hexanes, and allowed to slowly recrystallize in a $-20{ }^{\circ} \mathrm{C}$ freezer yielding red-orange single crystals that were used for single crystal X-ray diffraction analysis. 


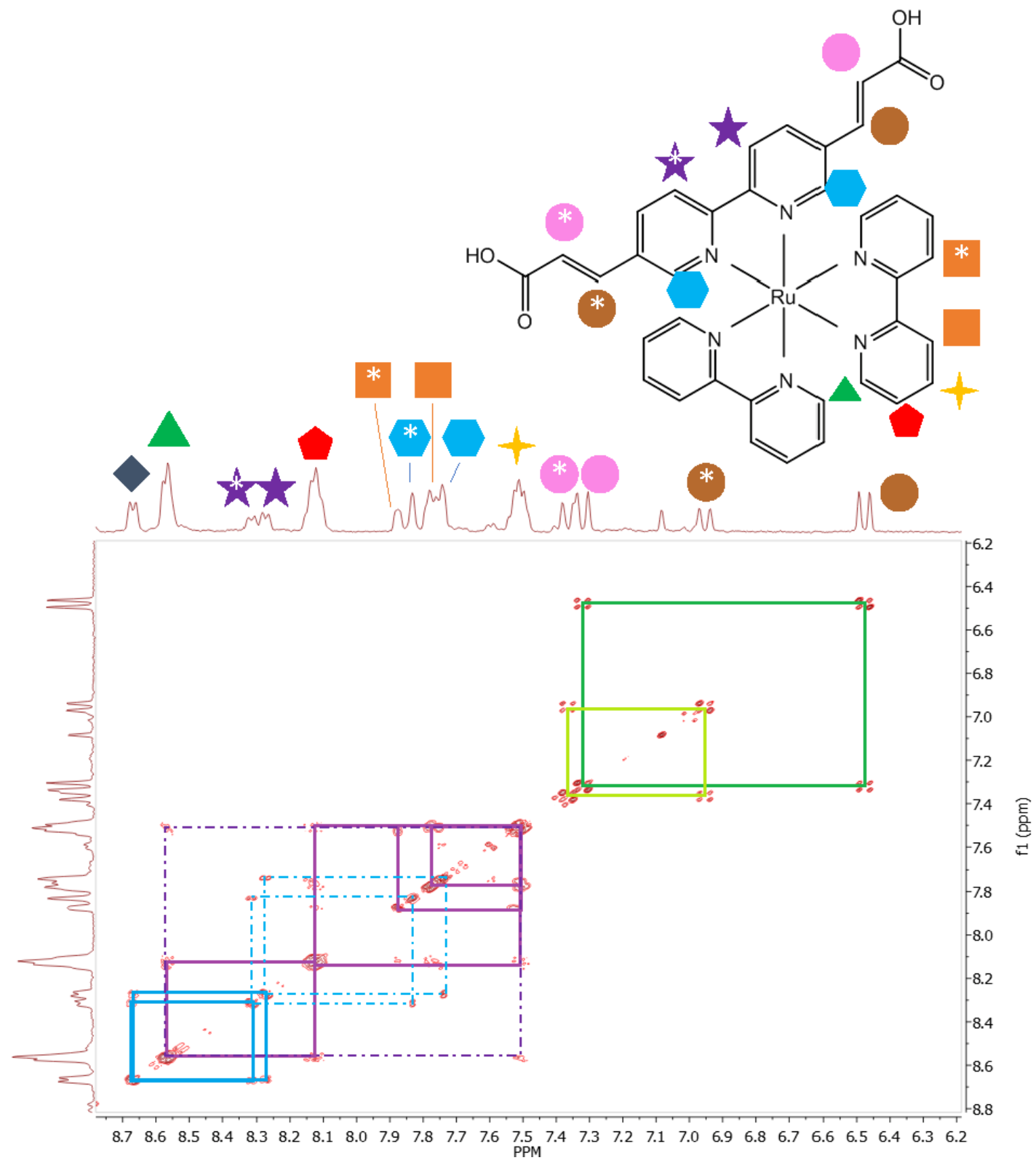

\section{General Assembly Method.}

The assembly method is identical for all quantum dot compositions. Typical conditions employed CdS QDs and 2,2'-bipyridine-5,5'-diacrylate-tBu as a linker precursor. From a toluene stock solution stored in a glovebox, 0.8 - $80 \mathrm{nmol}$ (8 typical) of QDs (1.0 eq.) are transferred to a glass Schlenk bomb with a magnetic stir bar. The solvent is removed by vacuum and the QDs are resuspended in $3 \mathrm{~mL} \mathrm{CH}_{2} \mathrm{Cl}_{2}$. Stock solutions of linker were prepared the day of use using $\mathrm{CH}_{2} \mathrm{Cl}_{2}$ for esterified linkers and DMF for bis-carboxylic acids. Using a microliter syringe 10 - 1,250 eq (typical 50 eq.) of linker are measured and added to the QD solution. For esterified linkers a solution of trifluoroacetic acid (TFA) in $\mathrm{CH}_{2} \mathrm{Cl}_{2}$ is prepared and 5 eq. per carboxylate (i.e., 100 - 12,500 eq. per QD, typical 500 eq.) of TFA is added. The 
solution is left to equilibrate for $1 \mathrm{~h}$ with stirring. Solvent and excess TFA are removed by vacuum and 2 $\mathrm{mL}$ of each toluene and DMF are added. The Schlenk bombs are sealed and brought out of the glovebox and are then transferred to an oil bath. The vessels are heated at $90{ }^{\circ} \mathrm{C}$ for up to $7 \mathrm{~d}$. Aggregates are isolated by centrifugation at $6,000 \mathrm{rpm}$ usually yielding a clear supernatant without the use of antisolvent. The solid is shaken with $5 \mathrm{~mL}$ acetonitrile and centrifuged again a total of three times.

\section{ICP-MS Details.}

Elemental analysis was performed using a Perkin Elmer NexION 2000B ICP-MS. Samples were dried and digested overnight in $67 \%$ ICP grade nitric acid then diluted to $2 \%$ concentration using $18 \mathrm{M} \Omega$ water and filtered. Samples were further quantitatively diluted to the $10-100 \mathrm{ppb}$ range with additional pure $2 \%$ nitric acid solution.

The chelation ability of bipyridine-linked aggregates was tested using this method. Four aggregate samples were prepared in total as described by the general assembly method, two at 50 eq. linker and two at 250 eq. linker. For each series a respective amount of $\mathrm{Ni}\left(\mathrm{PPh}_{3}\right)_{2} \mathrm{Cl}_{2}, 50$ or 250 eq, was added either before or after aggregation for a total of four samples. Prior to digestion samples were centrifuged at $10,000 \mathrm{rpm}$ to separate precipitate from supernatant and each phase was tested separately.

\section{DLS Details.}

Dynamic light scattering (DLS) measurements were performed using a Malvern Zetasizer Pro with a 632 $\mathrm{nm}$ laser, above the bandgap of the studied quantum dots to minimize fluorescent convolution. Samples were prepared in dilute solutions of toluene in a quartz cuvette and sonicated immediately prior to measurement at $22{ }^{\circ} \mathrm{C}$. Scattering data were fit using a cumulant model in the Malvern Zetasizer software.

\section{TEM Analysis.}

All imaging was done on a FEI Tecnai G2 F20 transmission electron microscope operated at $200 \mathrm{kV}$. Standard samples were prepared via drop-casting dilute aggregate suspension in toluene $(5 \mu \mathrm{L})$ onto ultrathin carbon film on a lacey carbon support film, 400 mesh, copper grids purchased from Ted Pella Inc, allowed to dry fully then placed under vacuum overnight. Tomography samples were prepared as previously described on carbon support film, 200 mesh, copper pinpointer grids purchased from Ted Pella Inc. Analysis of aggregates was done in Image $\mathrm{J}^{8}$ with the uncompressed. $\mathrm{dm} 3$ file with an average of 350 measurements (diameters and spacings) per average value reported. No enhancements or further processing was done to the images.

\section{Diffuse Reflectance Details.}

Diffuse reflectance data were measured using a Varian Cary 5000 with internal DRA-900 integrating sphere accessory. Data were acquired across the diffuse and specular range and calibrated to a high reflectance $\mathrm{BaSO}_{4}$ standard. Samples were prepared by drop casting concentrated QD solutions onto glass slides and spin coating until visibly opaque.

\section{Synchrotron Small Angle X-Ray Scattering Details.}

Small angle X-ray scattering (SAXS) was performed using beamline 1-5 of the Stanford Synchrotron Radiation Light Source at the SLAC National Accelerator Laboratory. Data were acquired using a $1 \mathrm{~m}$ detector distance configuration using a PILATUS 100K 2D detector and at $10.5 \mathrm{keV}$. Samples were prepared in $1 \mathrm{~mm}$ quartz cuvettes produced by Charles Supper Co at concentrations of about $5 \mathrm{mg} / \mathrm{mL}$ and sealed with epoxy. SAXS data were analyzed using SasView, an open source project developed in part by the NSF and NIST. ${ }^{9}$ The background was determined using a capillary filled with solvent as a baseline reference, and data were normalized to the beam-stop intensity. 


\section{Supplementary Data.}
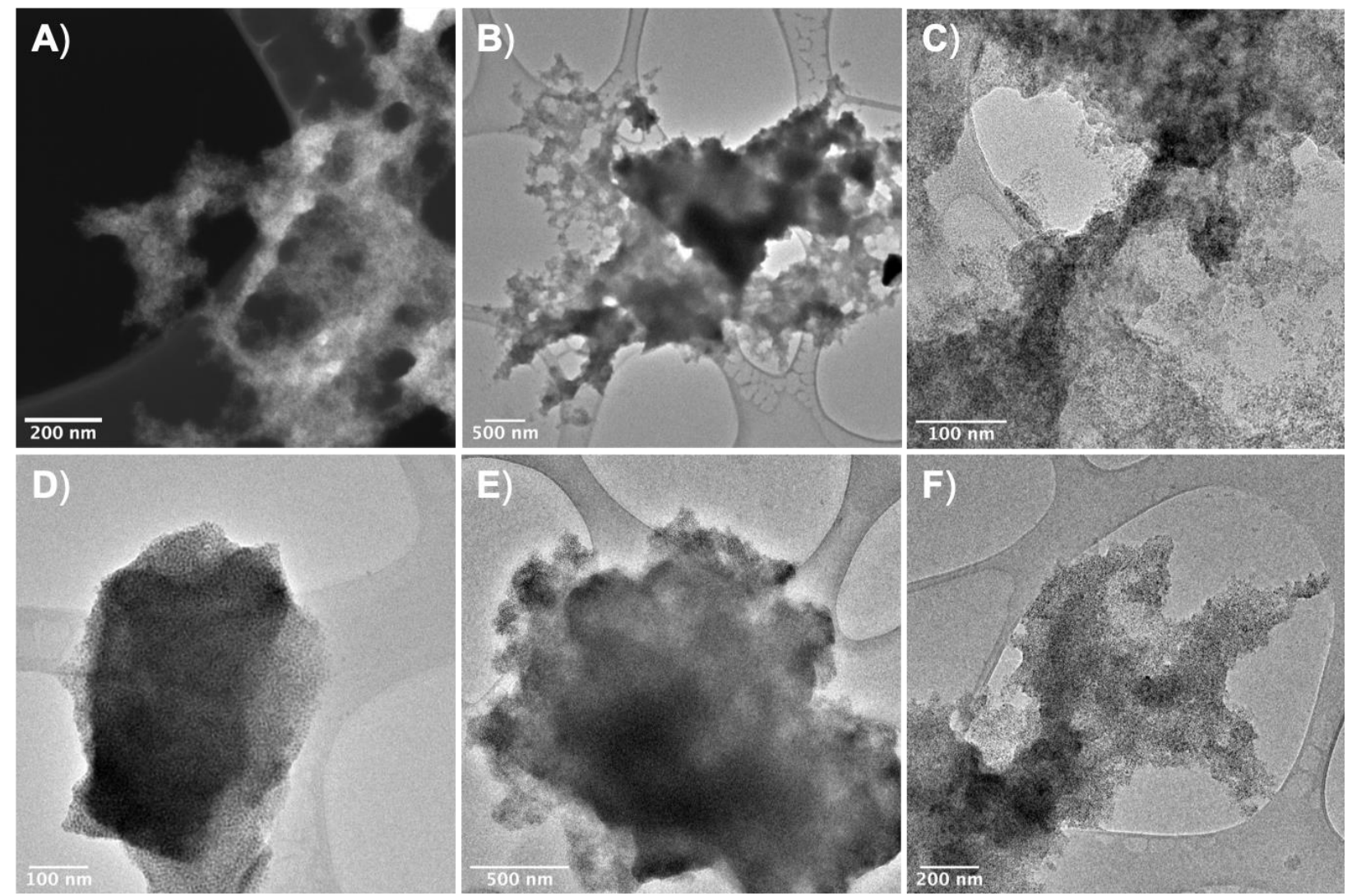

Figure S1. TEM images of amorphous QD aggregates after $1 \mathrm{~h}$ equilibration at $22{ }^{\circ} \mathrm{C}$ with varied linker equivalents 10 eq., 50 eq., and 250 eq. (A-C, respectively). TEM images using 50 eq. linker after 1, 4, and $7 \mathrm{~d}$ at $90{ }^{\circ} \mathrm{C}$ (D-F, respectively).

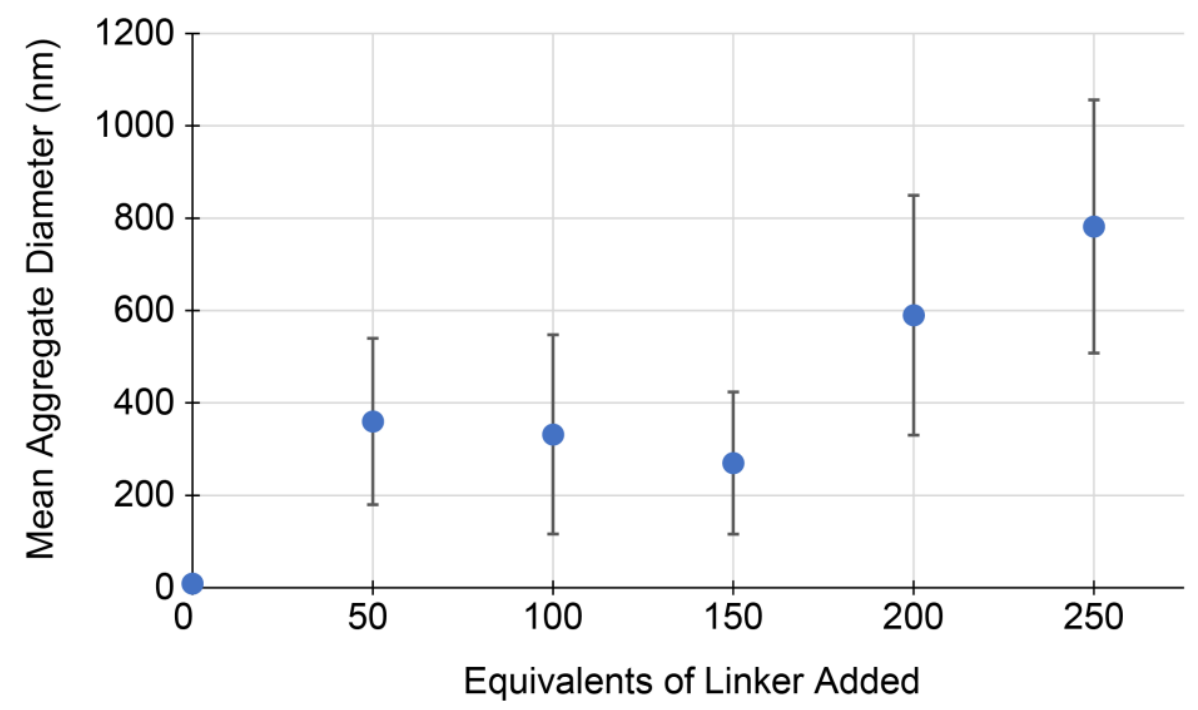

Figure S2. DLS data for CdS QD aggregates prior to thermal equilibration as a function of linker concentration. 
Table S1. Particle size and spacing analysis for CdS QDs.

\begin{tabular}{|c|c|c|c|c|}
\hline CdS & $\begin{array}{c}\text { Particle size } \\
(\mathbf{n m})\end{array}$ & $\begin{array}{c}\text { Center-center distance } \\
(\mathbf{n m})\end{array}$ & $\begin{array}{c}\text { Interparticle spacing } \\
(\mathbf{n m})\end{array}$ & $\begin{array}{c}\text { STDEV } \\
(\mathbf{n m})\end{array}$ \\
\hline QDs & 5.93 & 7.88 & 1.96 & 0.96 \\
\hline Aggregates & 5.31 & 7.07 & 1.76 & 1.14 \\
\hline
\end{tabular}

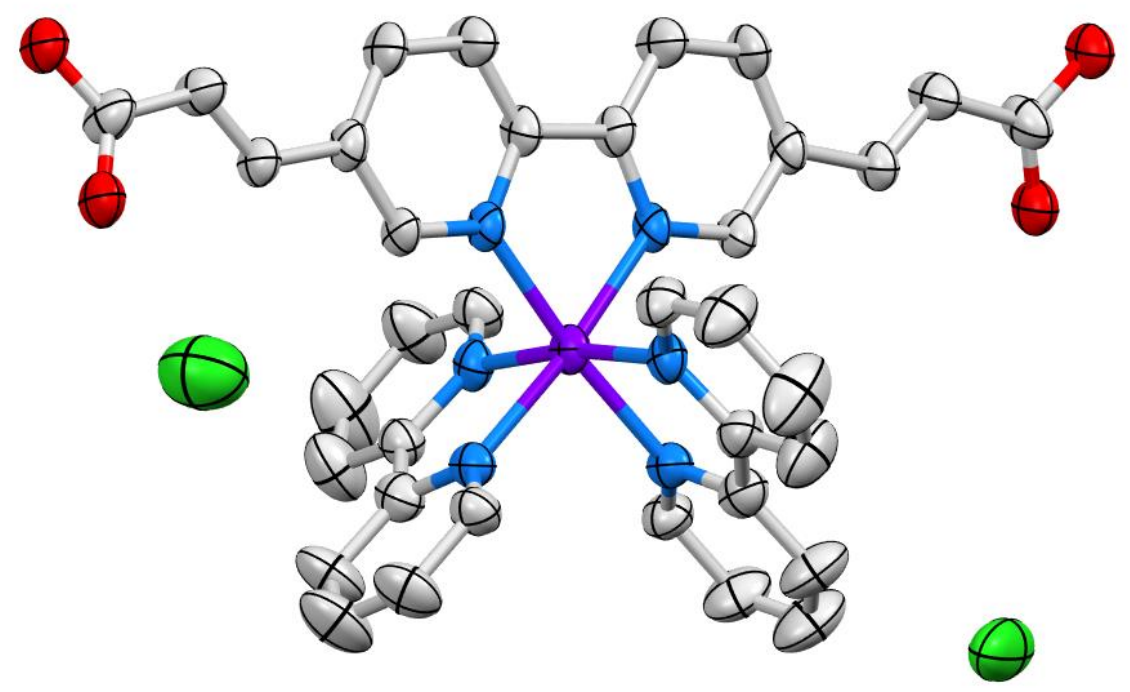

Figure S3. Single crystal X-ray diffraction structure of (bpy)2Ru(2,2'-bpy-5,5'-diacrylic acid). Hydrogen atoms omitted for clarity. Carbon (gray), oxygen (red), chlorine (green), nitrogen (blue), and ruthenium (purple).

Table S2. Crystal data table for (bpy $)_{2} \operatorname{Ru}\left(2,2^{\prime}-\right.$-bpy-5,5'-diacrylic acid $) \mathrm{Cl}_{2}$.

Identification code

Empirical formula

Formula weight

Temperature

Wavelength

Crystal system

Space group

Unit cell dimensions

Volume

Z

Density (calculated)

Absorption coefficient

$\mathrm{F}(000)$

Crystal size

Theta range for data collection

Index ranges

Reflections collected shelx

$\mathrm{C} 36 \mathrm{H} 28 \mathrm{Cl} 2 \mathrm{~N} 6 \mathrm{O} 4 \mathrm{Ru}$

780.61

$100(2) \mathrm{K}$

$0.71073 \AA$

Tetragonal

P $42 / \mathrm{n}$

$a=11.7526(5) \AA \quad \alpha=90^{\circ}$.

$\mathrm{b}=11.7526(5) \AA \quad \beta=90^{\circ}$.

$\mathrm{c}=32.1926(16) \AA \quad \gamma=90^{\circ}$.

4446.6(4) ^3

4

$1.166 \mathrm{Mg} / \mathrm{m} 3$

$0.511 \mathrm{~mm}^{-1}$

1584

$0.160 \times 0.090 \times 0.080 \mathrm{~mm} 3$

1.845 to $28.343^{\circ}$.

$-11<=\mathrm{h}<=11,-15<=\mathrm{k}<=15,-42<=\mathrm{l}<=42$

11013 
Independent reflections

Completeness to theta $=25.000^{\circ} 99.9 \%$

Refinement method

$5561[\mathrm{R}(\mathrm{int})=0.0392]$

Data / restraints / parameters

Goodness-of-fit on F2

Full-matrix least-squares on F2

Final $\mathrm{R}$ indices [I $>2 \operatorname{sigma}(\mathrm{I})]$

$5561 / 31 / 239$

$\mathrm{R}$ indices (all data)

Largest diff. peak and hole

1.145

$\mathrm{R} 1=0.0794, \mathrm{wR} 2=0.1772$

$\mathrm{R} 1=0.1186, \mathrm{wR} 2=0.1921$

1.382 and -0.892 e. $\AA-3$
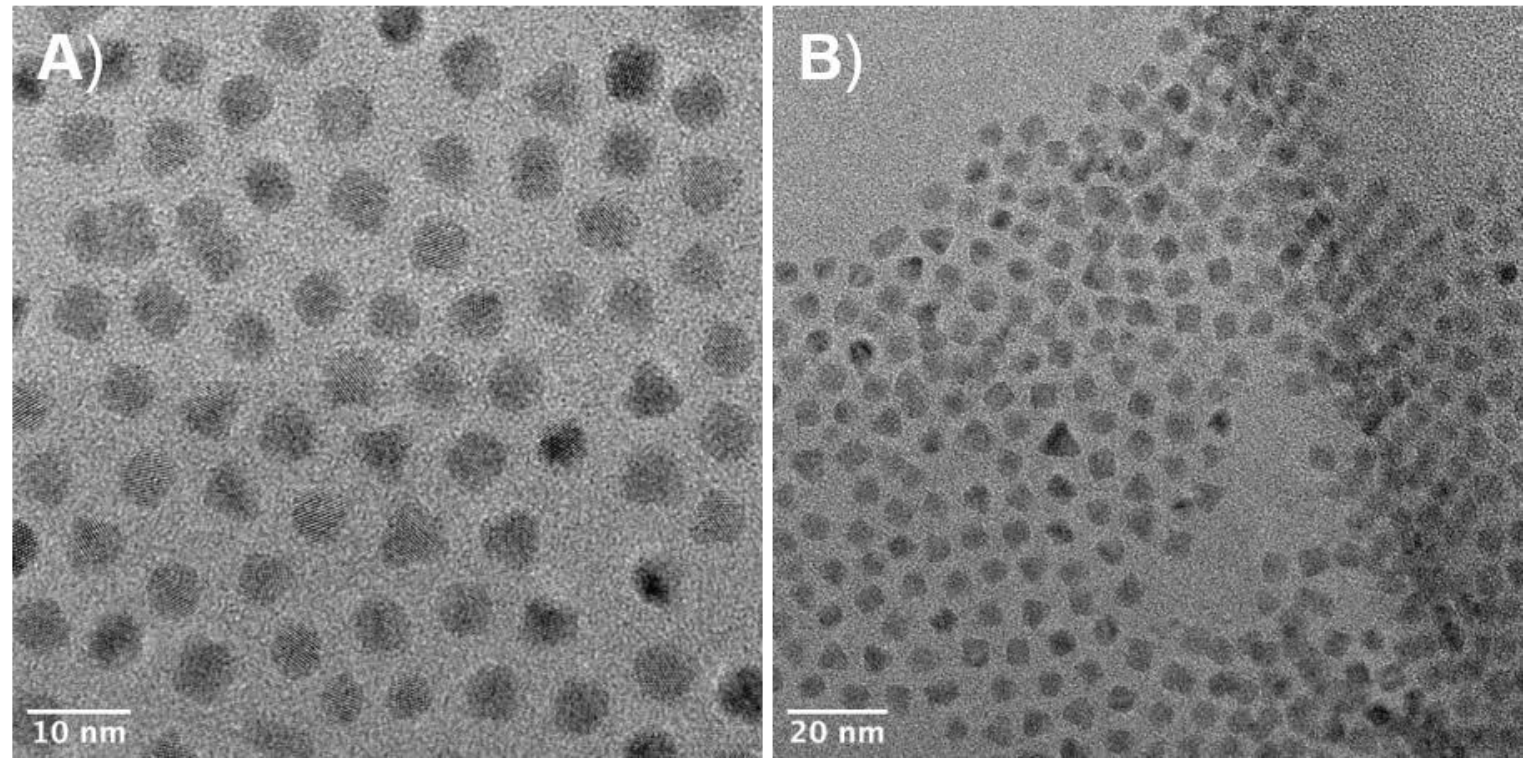

Figure S4. TEM images of CdS quantum dots that have been subjected to standard assembly conditions using a monofunctional carboxylic acid, cinnamic acid, which does not lead to productive assembly. The particles etch under these conditions, resulting in a more spherical particle shape and improved hexagonal packing.

Table S3. SAXS fitting.

\begin{tabular}{|c|c|c|c|c|}
\hline & QD SAXS & QD TEM & Assembly SAXS & Assembly TEM \\
\hline Diameter $(\mathrm{nm})$ & $5.96 \pm 0.55$ & $5.93 \pm 0.65$ & $5.62 \pm 0.62$ & $5.31 \pm 0.67$ \\
\hline Spacing $(\mathrm{nm})$ & $\mathrm{n} / \mathrm{a}$ & $1.96 \pm 0.96$ & 1.84 & $1.76 \pm 1.14$ \\
\hline
\end{tabular}

SAXS data were fit using SasView software using unweighted least squares regression. Background subtraction was performed using a capillary containing only the solvent, and data were normalized to the beam-stop intensity. Polydispersity was modeled as a gaussian distribution, ranges represent one standard deviation. Polydispersity in spacing was not fit.

Sphere Model: A. Guinier and G. Fournet, Small-Angle Scattering of X-Rays, John Wiley and Sons, New York, 1955. ${ }^{10}$ 
Pearl-Necklace Model: R Schweins and K Huber, Particle Scattering Factor of Pearl Necklace Chains, Macromol. Symp., 2004, 211, 25-42. ${ }^{11}$

\section{Structure Factor Analysis}

The procedure for extracting a structure factor for quantum dot films has been previously investigated by Murray, Kagan, and Bawendi as described by Klug and Alexander. ${ }^{12,13}$ Here we apply the same approach for our colloidally stable assemblies.

General total scattering by $\mathrm{N}$ particles is described by:

$$
I(q)=I(q)_{0} N F^{2}(q) S(q)
$$

Where $\mathrm{F}^{2}(\mathrm{q})$ is the form factor of an individual particle and $\mathrm{S}(\mathrm{q})$ is the structure factor relating interparticle order and scattering interference.

By first determining the form factor via a dispersed (i.e. uncorrelated) nanoparticle solution where $S(q)$ Solv $=1$ the structure factor of the assembly may then be solved for directly by dividing the assembled total scattering by the dispersed (experimental) nanoparticle form factor:

$$
\frac{I(q)_{\text {Assembly }}}{I(q)_{0} N F^{2}(q)}=S(q)_{\text {Assembly }}
$$

Plot of Experimental Structure Factor S(q):

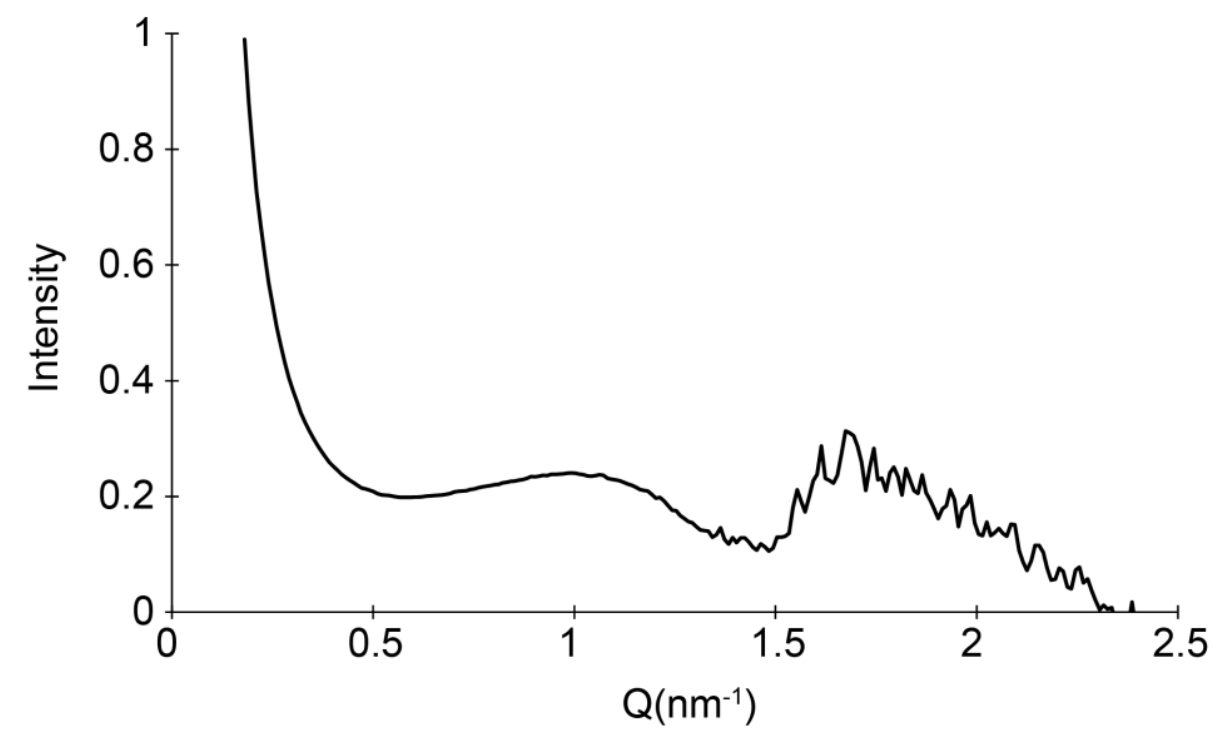




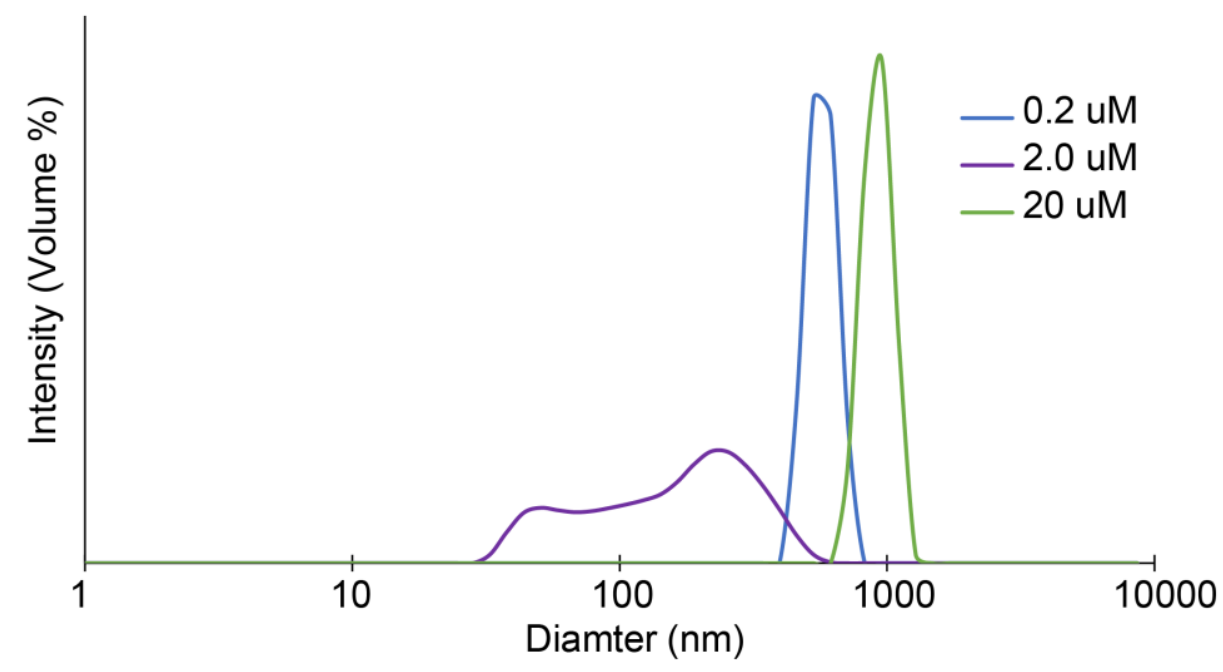

Figure S5. DLS data for CdS assemblies suspended in toluene as a function of QD concentration during assembly. For all trials the standard linking procedure was followed as described using the modified QD amount with 50 eq of 2,2'-bpy-5,5'-diacrylic acid.

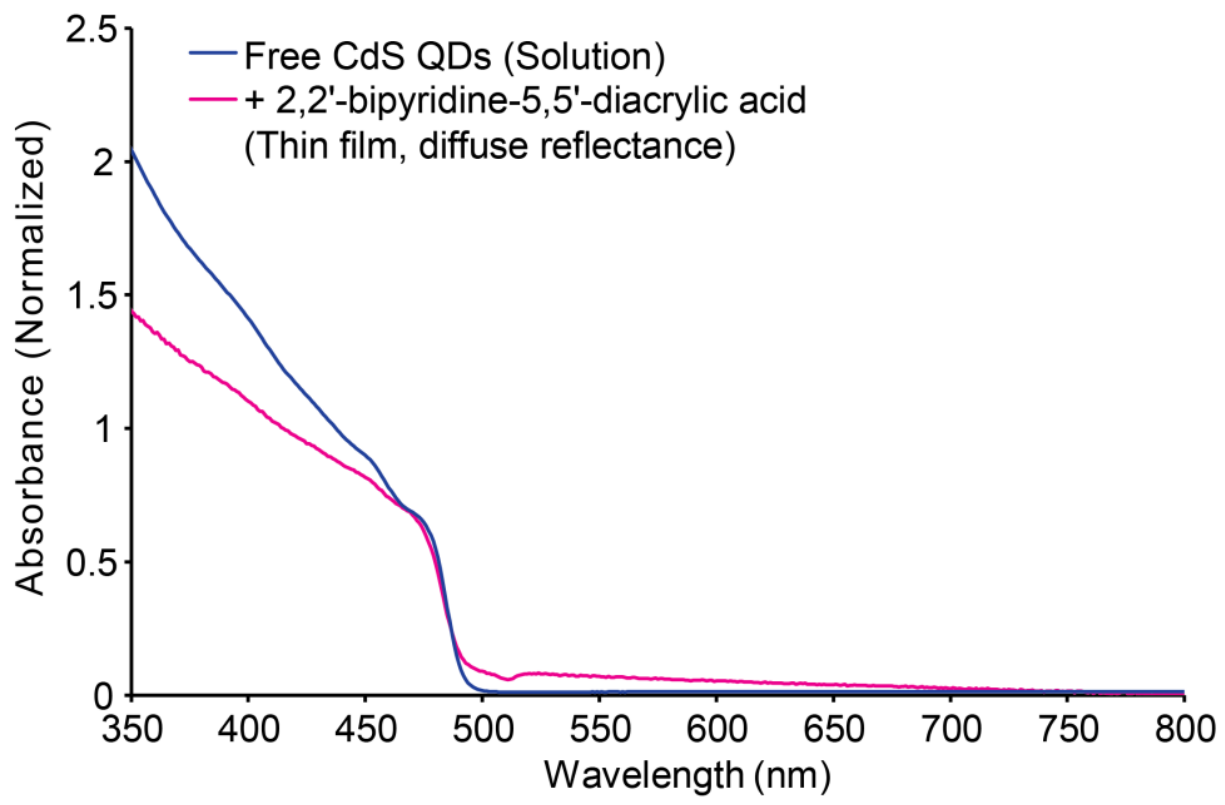

Figure S6. Solution phase UV-Vis spectrum of CdS QDs (blue) and diffuse reflectance spectrum of a thin film of CdS QDs linked by 2,2'-bipyridine-5,5'-diacrylic acid. 
Table S4. Particle size and spacing analysis for different linkers.

\begin{tabular}{|c|c|c|c|}
\hline & $\begin{array}{c}\text { Center- } \\
\text { center } \\
\text { distance } \\
\mathbf{( n m )}\end{array}$ & $\begin{array}{c}\text { Interparticle } \\
\text { spacing } \\
\mathbf{( n m})\end{array}$ & $\begin{array}{c}\text { Theoretical Spacing } \\
\text { (crystallographic } \\
\text { estimates from } \\
\text { CCDC) }\end{array}$ \\
\hline $\mathbf{2 , \mathbf { 2 } ^ { \prime } \text { -bipyridine-4,4'-dicarboxylic acid }}$ & 7.60 & $2.28 \pm 0.89$ & 1.07 \\
\hline Terephthalic acid & 7.48 & $2.17 \pm 0.83$ & 0.73 \\
\hline Dodecanedioic acid & 6.88 & $1.57 \pm 0.80$ & 1.61 *est \\
\hline $\mathbf{2 , 2}$ '-biphenyl-5,5'-diacrylic acid & 7.01 & $1.70 \pm 0.83$ & 1.68 \\
\hline
\end{tabular}

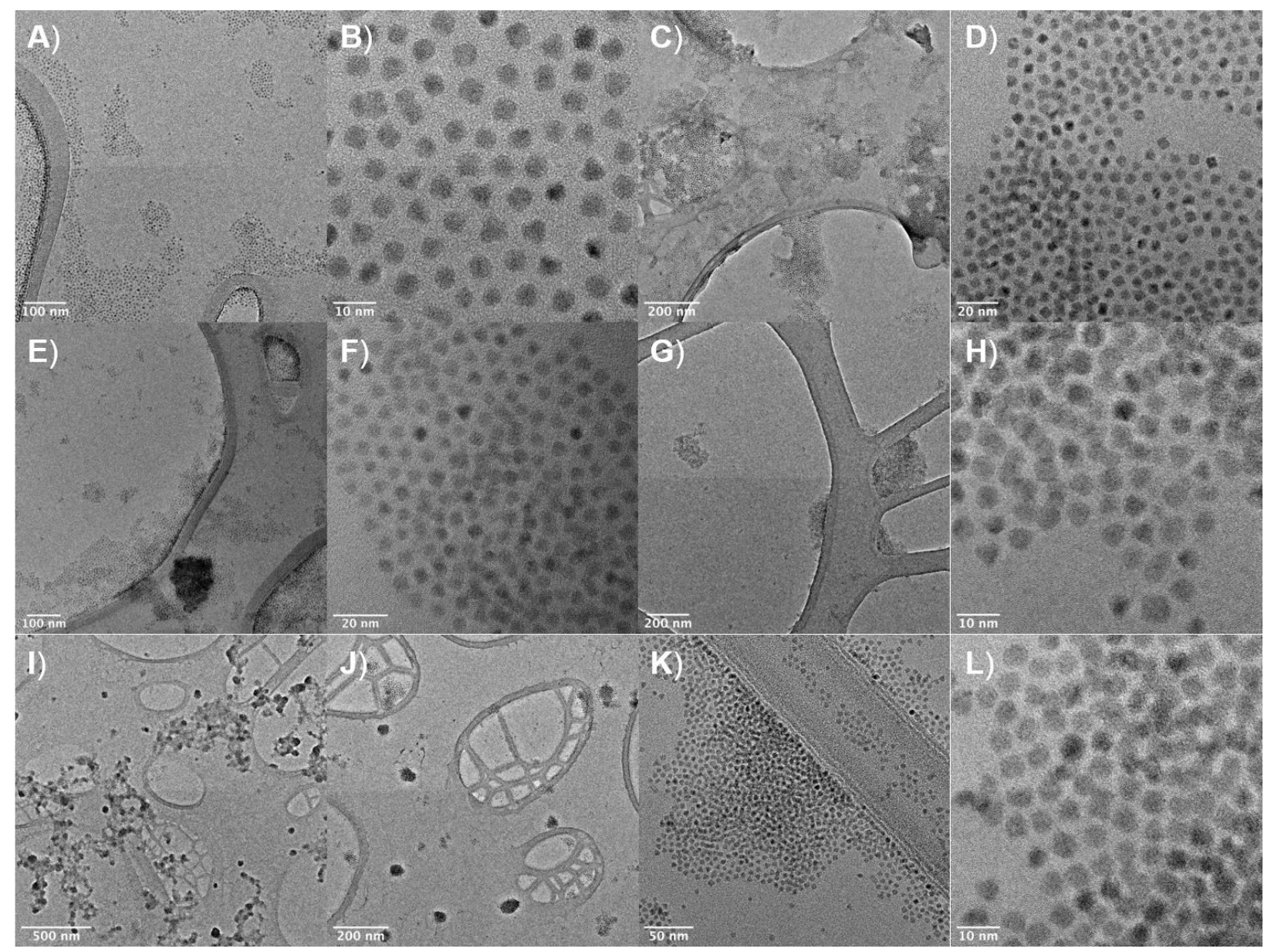

Figure S7. TEM images of particles following treatment of CdS QDs with different linkers. (A-D) Terephthalic acid. (E, F) 2,2'-bipyridine-4,4'-dicarboxylic acid. (G-J) Dodecanedioic acid. (K, L) 2,2'biphenyl-5,5'-diacrylic acid. A, B, E- H, and $\mathrm{K}, \mathrm{L}$ are of reaction precipitates and C, D, I, J are of reaction supernatants. 

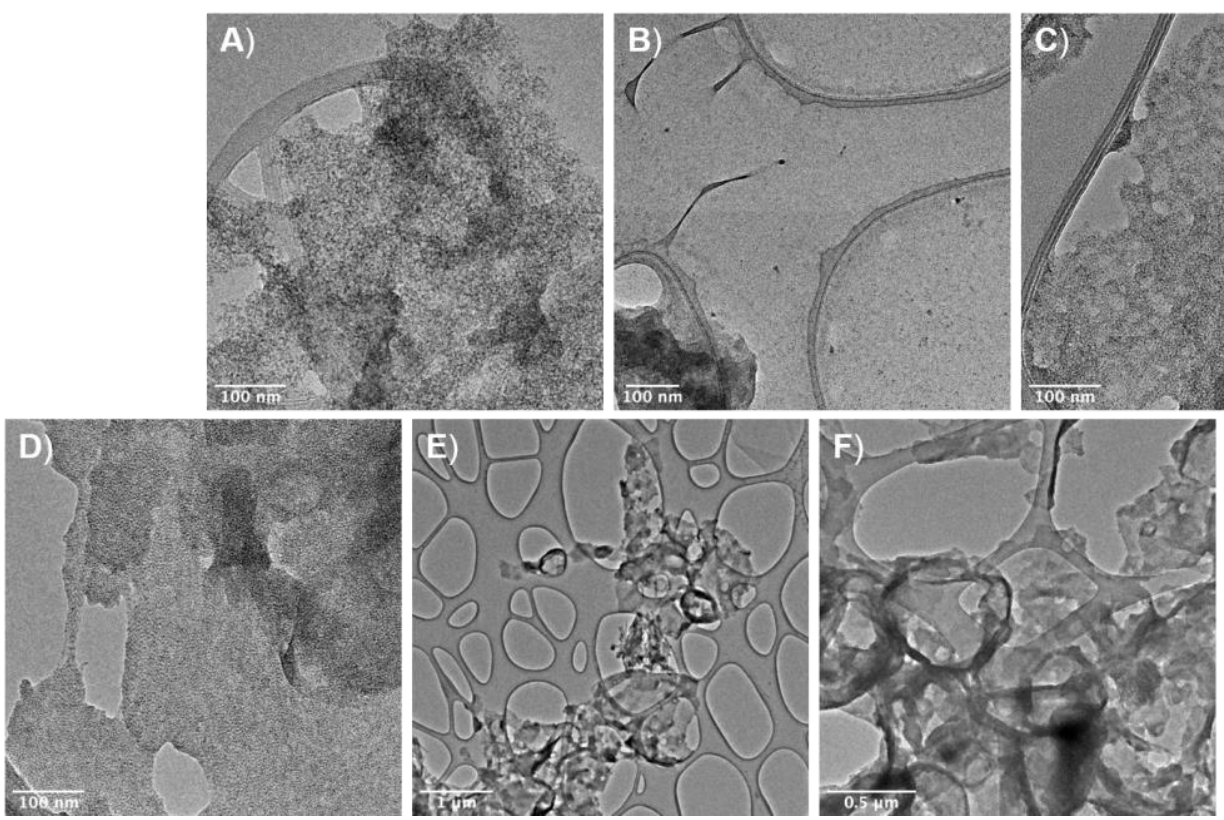
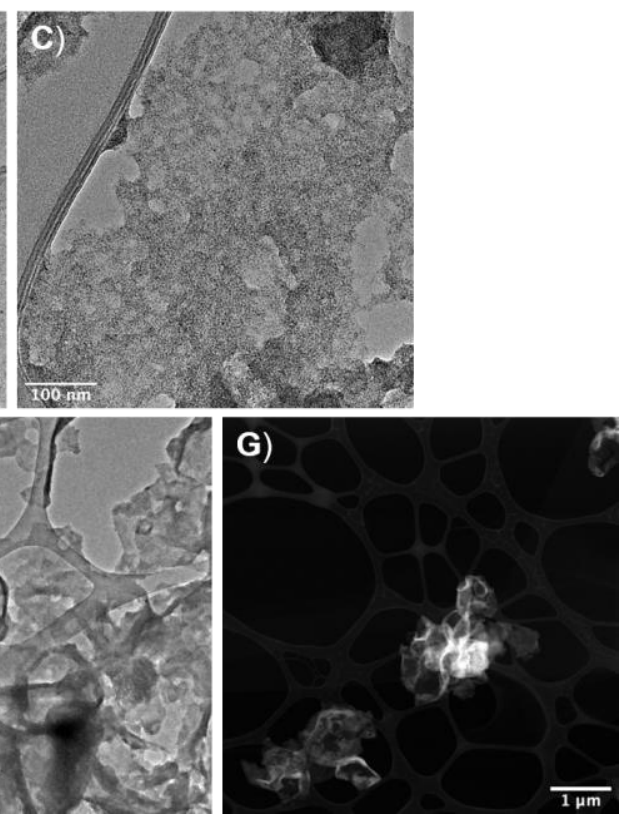

Figure S8. TEM images of assemblies prepared from InP/ZnSe (A), InP clusters (B), and CdSe (C-G) QDs using standard conditions.

Table S5. Particle size and spacing analysis for CdSe and InP/ZnSe QDs after aggregation.

\begin{tabular}{|c|c|c|c|c|}
\hline Aggregates & $\begin{array}{c}\text { Particle size } \\
(\mathbf{n m})\end{array}$ & $\begin{array}{c}\text { Center-center distance } \\
(\mathbf{n m})\end{array}$ & $\begin{array}{c}\text { Interparticle spacing } \\
(\mathbf{n m})\end{array}$ & $\begin{array}{c}\text { STDEV } \\
(\mathbf{n m})\end{array}$ \\
\hline $\mathbf{I n P}$ & 3.20 & 4.78 & 1.58 & 0.83 \\
\hline $\mathbf{C d S e}$ & 2.81 & 4.45 & 1.63 & 0.73 \\
\hline
\end{tabular}
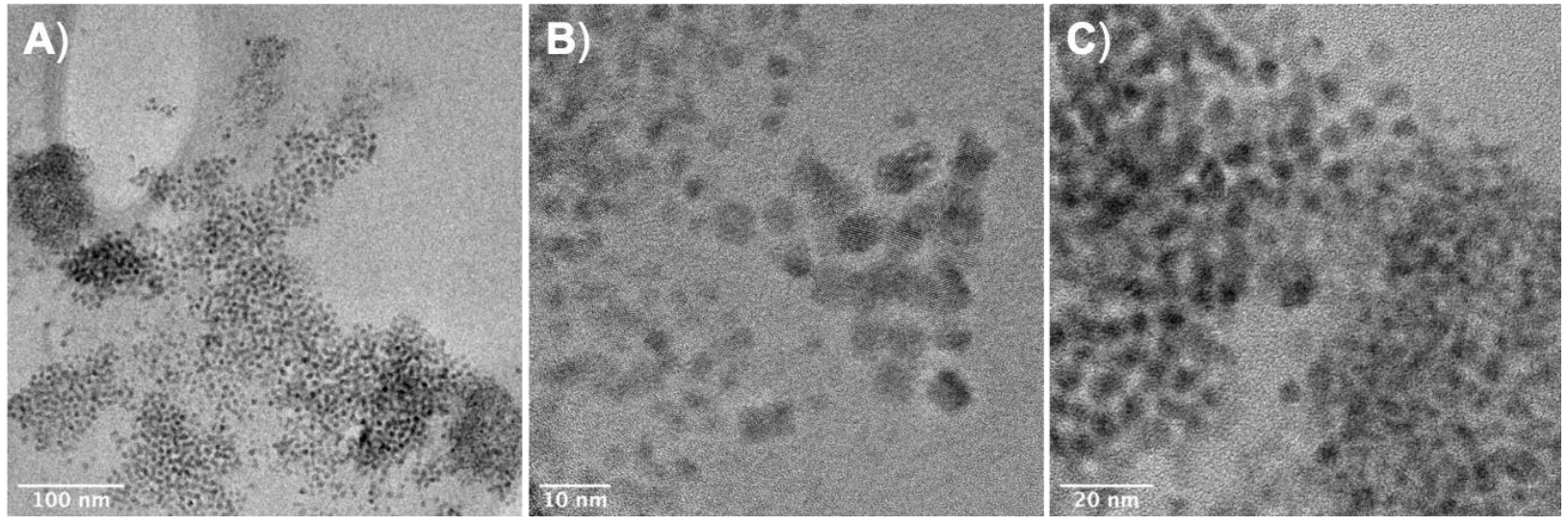

Figure S9. TEM images of assemblies prepared from InP/ZnSe QDs showing segregation of core and core/shell QDs in separate structures. 

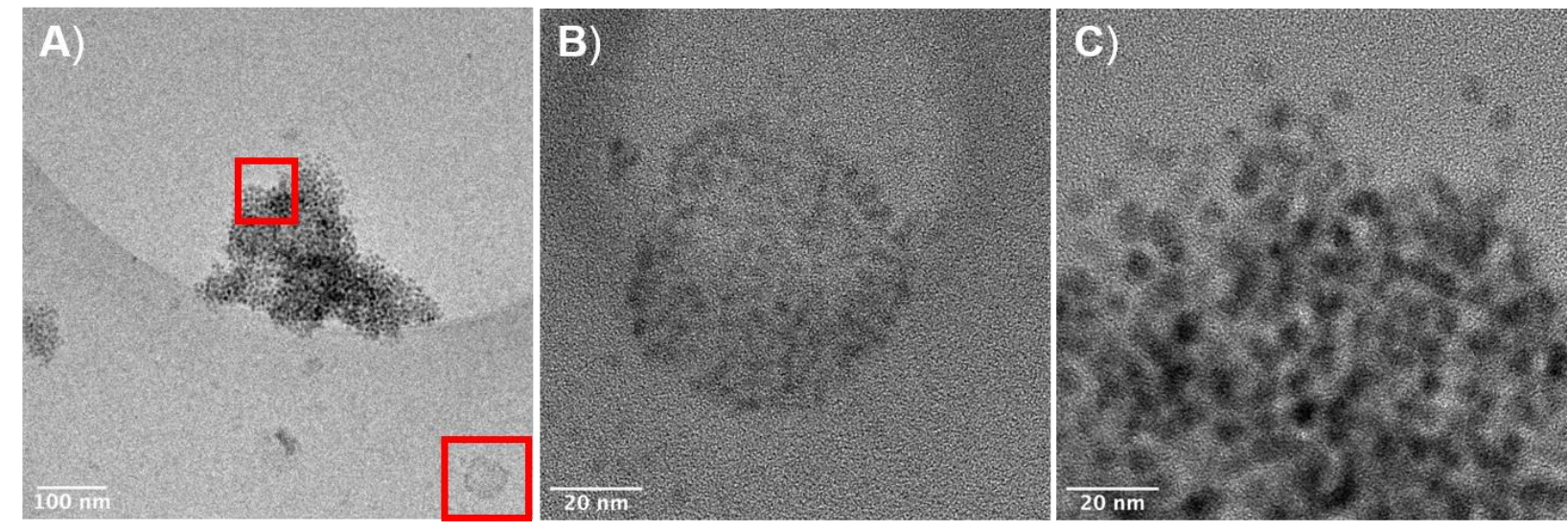

Figure S10. TEM images of assemblies prepared from polydisperse CdS QDs showing segregation of two QD sizes into separate structures. B) and C) are zoomed in regions from the highlighted regions shown in A).
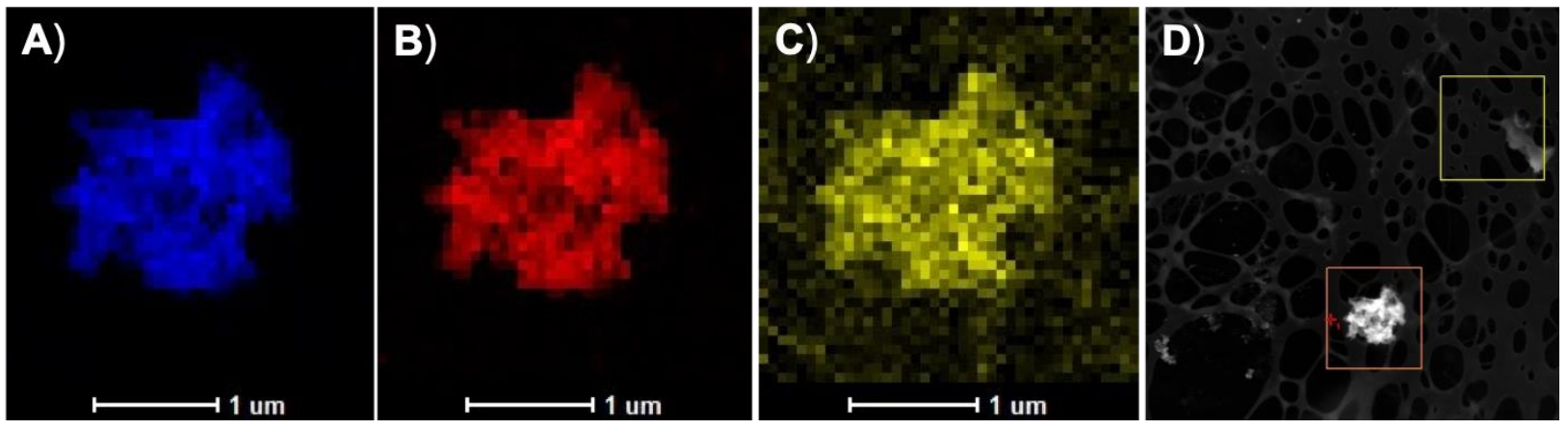

Figure S11. EDS mapping of CdS assemblies exposed to $\mathrm{Ni}^{2+}$ showing co-localization of Cd (blue), $\mathrm{S}$ (red), and Ni (yellow). 


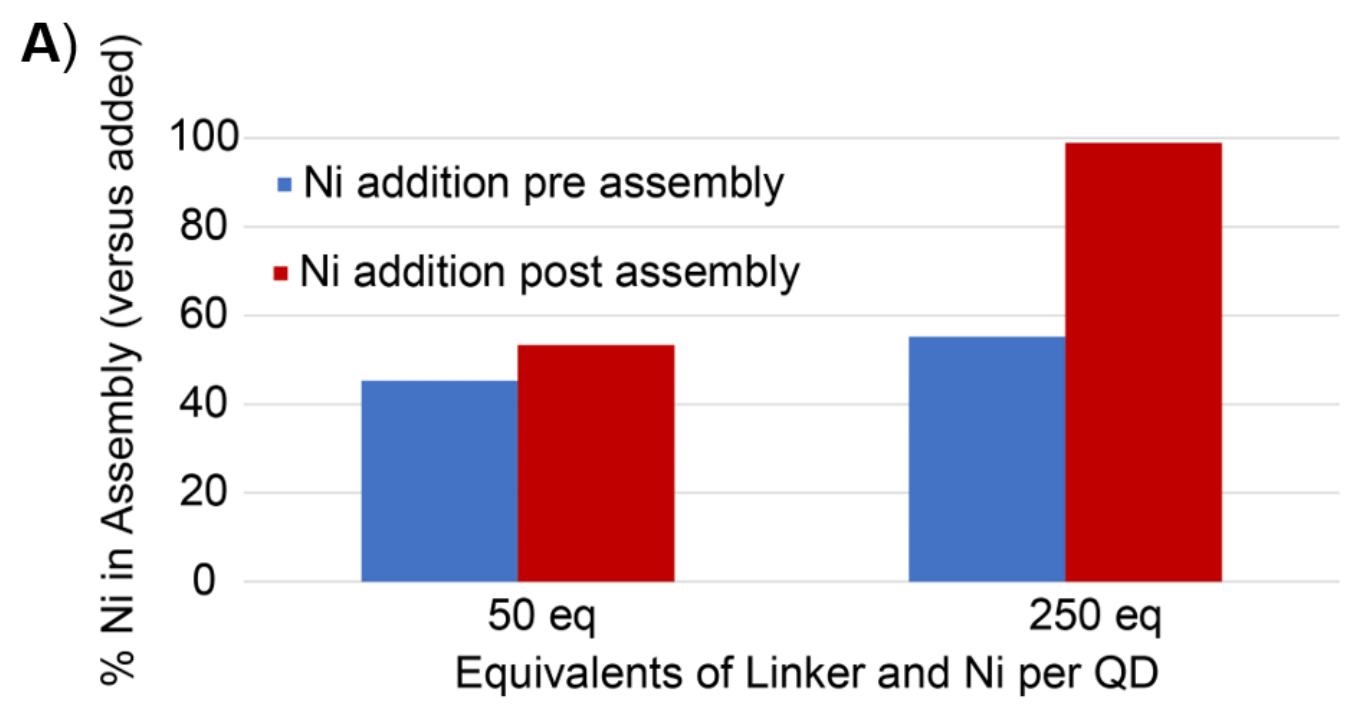

B)

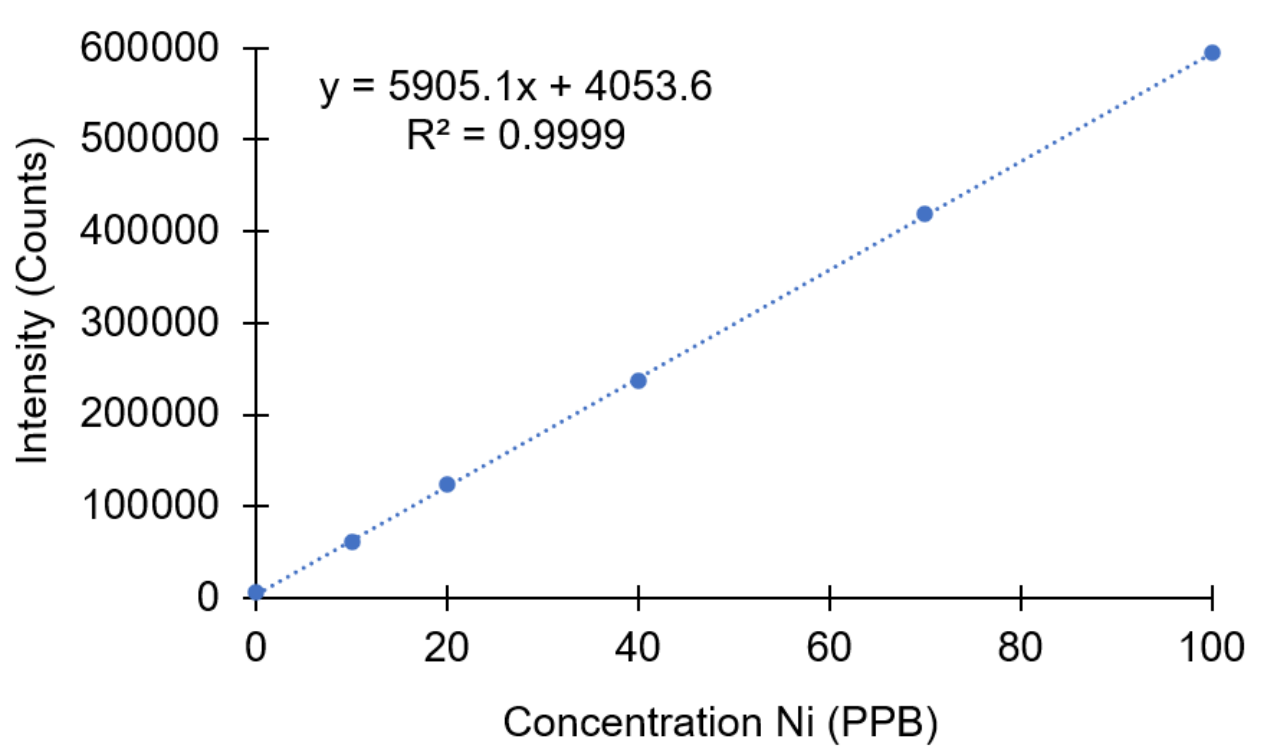

Figure S12. A) ICP-MS data quantifying $\mathrm{Ni}^{2+}$ uptake in $\mathrm{CdS}$ assemblies. In the case of Ni addition preassembly, $\mathrm{NiCl}_{2}\left(\mathrm{PPh}_{3}\right)_{2}$ was added to a solution of the bpy-diester before addition to the QDs. In the case of $\mathrm{Ni}$ addition post-assembly, $\mathrm{NiCl}_{2}\left(\mathrm{PPh}_{3}\right)_{2}$ was added to a suspension of the aggregates with stirring. The solution was allowed to equilibrate for $1 \mathrm{hr}$ and then the aggregates were precipitated and washed. In all cases, ICP analysis were performed on both the isolated aggregates as well as the supernatant to ensure quantitative Ni recovery. B) External calibration curve used for Ni quantitation. 

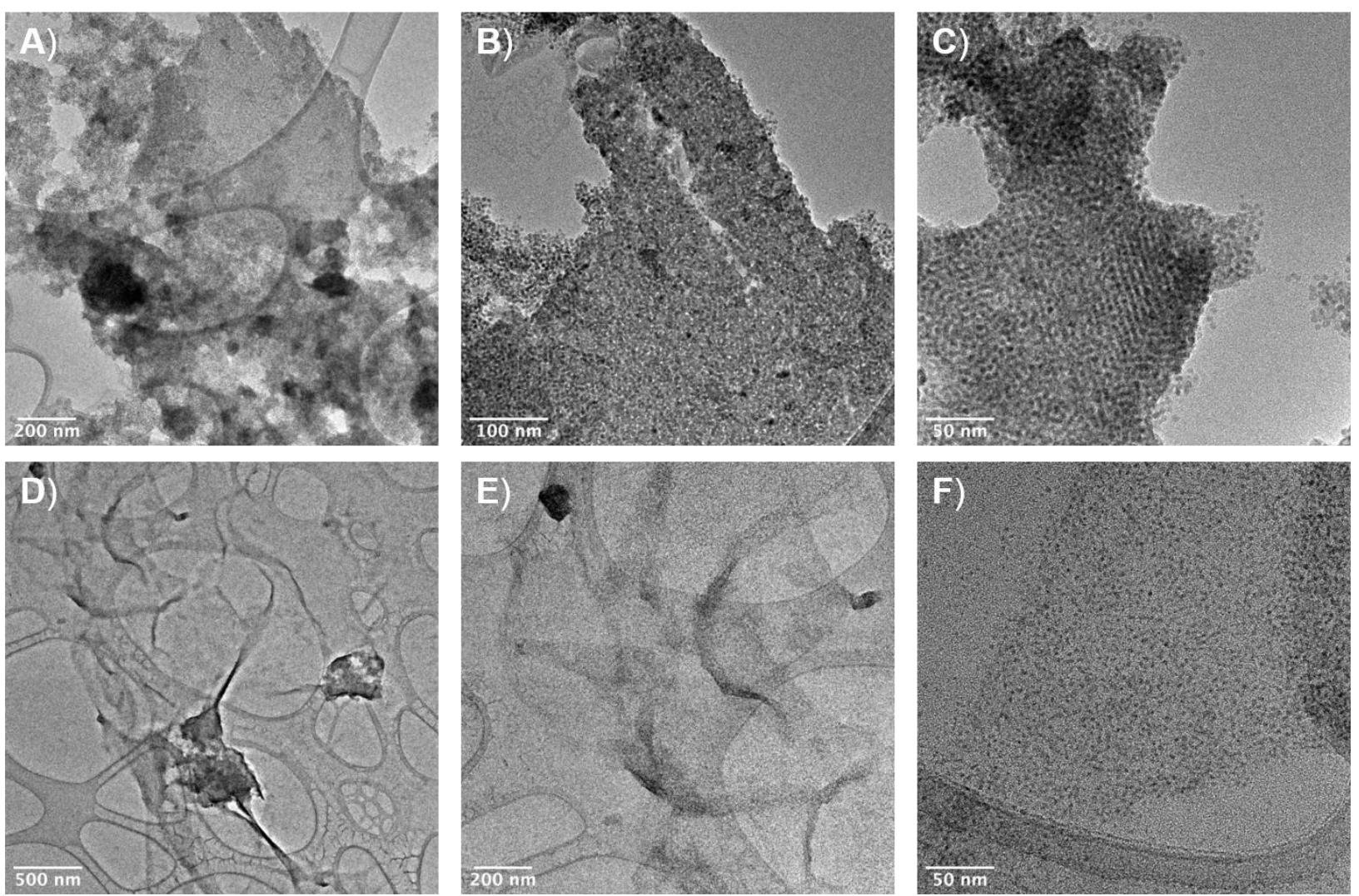

Figure S13. Additional TEM images for CdS (A-C) and CdSe (D-F) QDs assembled using 10 eq. 2,2'bipyridine-5,5'-diacrylic acid. 

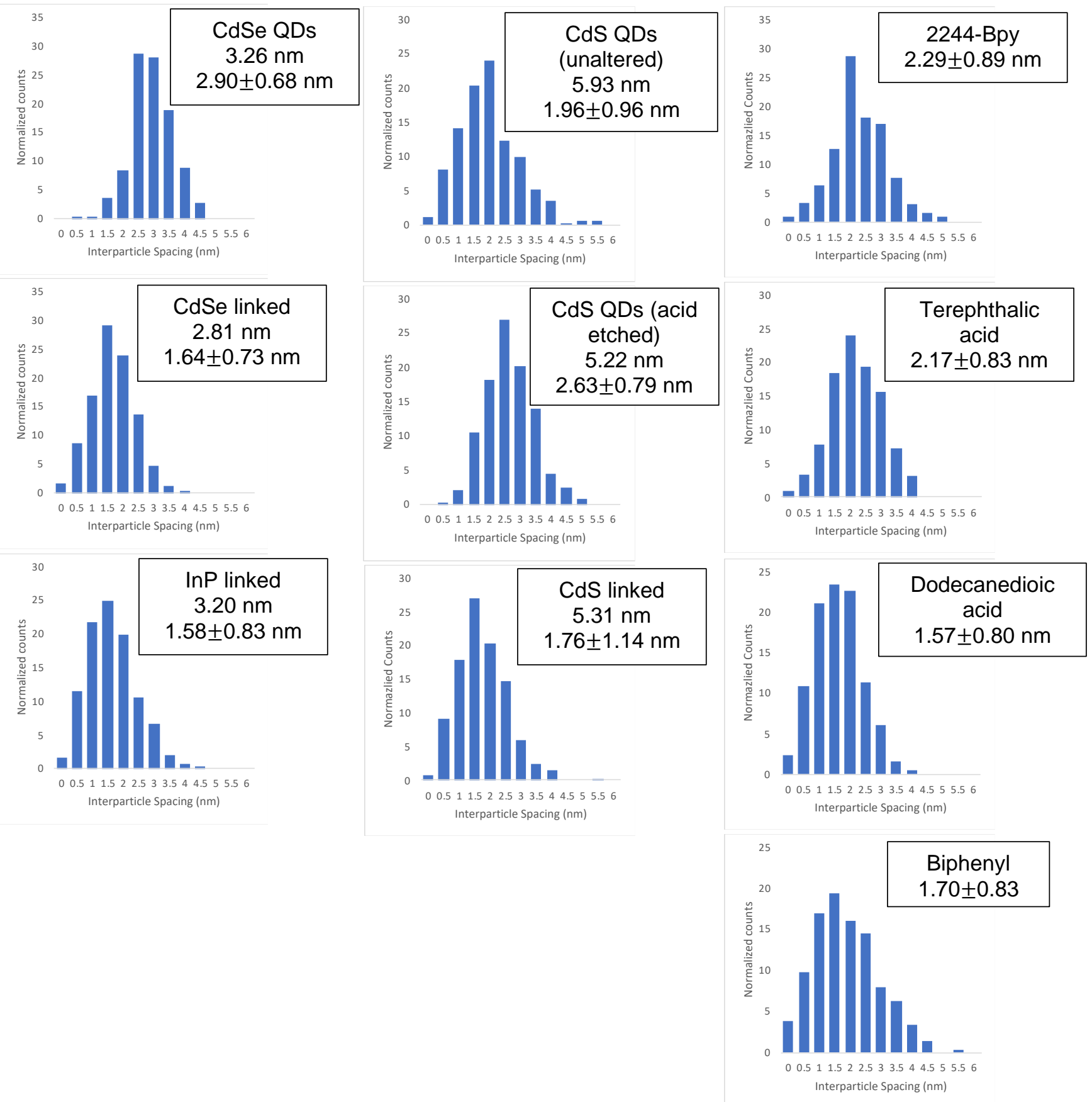

Figure S14. Histograms of particle spacing for aggregates and QDs of varying core compositions and histograms of CdS cores with different linkers. All histograms are scaled to a total count of 100 so that distributions are comparable. 


\section{References}

(1) Ritchhart, A.; Cossairt, B. M. Templated Growth of InP Nanocrystals with a Polytwistane Structure. Angew. Chem. Int. Ed. 2018, 57, 1908-1912.

(2) Yu, W. W.; Qu, L.; Guo, W.; Peng, X. Experimental Determination of the Extinction Coefficient of CdTe, CdSe, and CdS Nanocrystals. Chem. Mater. 2003, 15, 2854-2860.

(3) Xie, L.; Shen, Y.; Franke, D.; Sebastián, V.; Bawendi, M. G.; Jensen, K. F. Characterization of Indium Phosphide Quantum Dot Growth Intermediates Using MALDI-TOF Mass Spectrometry. $J$. Am. Chem. Soc. 2016, 138, 13469-13472.

(4) S. Hamachi, L.; Yang, H.; Plante, I. J.-L.; Saenz, N.; Qian, K.; P. Campos, M.; T. Cleveland, G.; Rreza, I.; Oza, A.; Walravens, W.; M. Chan, E.; Hens, Z.; C. Crowther, A.; S. Owen, J. Precursor Reaction Kinetics Control Compositional Grading and Size of CdSe 1-x S x Nanocrystal Heterostructures. Chem. Sci. 2019, 10, 6539-6552.

(5) Lim, J.; Bae, W. K.; Lee, D.; Nam, M. K.; Jung, J.; Lee, C.; Char, K.; Lee, S. InP@ZnSeS, Core@Composition Gradient Shell Quantum Dots with Enhanced Stability. Chem. Mater. 2011, $23,4459-4463$.

(6) Ali, A.; Hussain, M.; Malik, I.; Villinger, A.; Fischer, C.; Langer, P. Double Heck Cross-Coupling Reactions of Dibrominated Pyridines. Helv. Chim. Acta 2010, 93, 1764-1772.

(7) Li, H. J.; Wang, L. Triethanolamine as an Efficient and Reusable Base, Ligand and Reaction Medium for Phosphane-Free Palladium-Catalyzed Heck Reactions. Eur. J. Org. Chem. 2006, 2006, 5099-5102.

(8) Schneider, C. A.; Rasband, W. S.; Eliceiri, K. W. NIH Image to ImageJ: 25 Years of Image Analysis. Nat. Methods 2012, 9, 671-675.

(9) SasView. SasView https://sasview.github.io/.

(10) Guinier, A.; Fournet, G. Small-Angle Scattering of X-Rays. John Wiley \& Sons, New York, 1955.

(11) Schweins, R.; Huber, K. Particle Scattering Factor of Pearl Necklace Chains. Macromol. Symp. 2004, 211, 25-42.

(12) Murray, C. B.; Kagan, C. R.; Bawendi, M. G. Synthesis and Characterization of Monodisperse Nanocrystals and Close-Packed Nanocrystal Assemblies. Annu. Rev. Mater. Sci. 2000, 30, 545610.

(13) Klug, H. P.; Alexander, L. E. X-Ray Diffraction Procedures for Polycrystalline and Amorphous Materials. John Wiley \& Sons, New York, 1974. 